\title{
Convergent evolution of levee building behavior among distantly related ant species in a floodplain ant assemblage
}

\author{
E. G. LeBrun • M. Moffett • D. A. Holway
}

Received: 27 April 2010/Revised: 7 December 2010/ Accepted: 6 January 2011 / Published online: 28 January 2011

(C) The Author(s) 2011. This article is published with open access at Springerlink.com

\begin{abstract}
Flooding impacts ground nesting ant colonies by destroying the infrastructure housing and organizing societal function. Here, we report the convergent evolution in distantly related ant species of a behavioral trait that minimizes costs of flooding: the construction of earthen levees around nest entrances. In a South American floodplain ecosystem, we observed five ant species constructing prominent earthen berms encircling nest entrances shortly after large rainfall events. In four of these species, experimental flooding of nests demonstrated that earthen berms sufficed to prevent floodwaters from entering the below ground portions of the nest. Additional manipulations revealed that levee breaching caused, pronounced, and extended reductions in food collection for two distantly related species. Foraging was preempted by the allocation of workers to repair the internal structure of the nest. These findings represent convergent evolution of a functionally important nest construction behavior in response to comparable selective forces.
\end{abstract}

E. G. LeBrun $(\bowtie)$

Brackenridge Field Laboratory, Section of Integrative Biology, University of Texas at Austin, 2907 Lake Austin Blvd, Austin, TX 78703, USA

e-mail: elebrun@mail.utexas.edu

\section{Moffett}

Department of Entomology, NMNH, Smithsonian Institution, Washington, DC, USA

e-mail: naturalist@erols.com

D. A. Holway

Division of Biological Sciences, University of California

at San Diego, La Jolla, CA, USA

e-mail: dholway@biomail.ucsd.edu
Keywords Formicidae $\cdot$ Nest flooding $\cdot$ Levees . Extended phenotype $\cdot$ Convergent evolution

\section{Introduction}

Ground-nesting insect societies face challenges similar to those confronting human societies when colonizing floodplain environments. Without means to prevent flooding, frequent inundation makes a non-nomadic lifestyle impossible, because, in addition to loss of life, infrastructure repairs become prohibitively costly. As well as potentially drowning the colony, flooding collapses internal galleries and tunnels that house these insect societies and that help to organize their divisions of labor (Hölldobler and Wilson, 1990). Thus, flooding can exert an important selective pressure on ground-nesting insect societies and favor traits that minimize the effects of inundation on colony survival and function. As the most diverse and abundant group of ground-nesting, eusocial insects, ants have evolved a variety of behavioral responses to flooding that includes rafting (Lude et al., 1999; Morrill, 1974), nest evacuation (Wilson, 1986), bailing behaviors (Klein et al., 1993; Maschwitz and Moog, 2000), and physiological tolerance (for additional examples see Moffett, 2010; Nielsen et al., 2003, 2006). Here we report the convergent evolution among distantly related species of an additional behavioral adaptation to minimize the costs of flooding: the construction of earthen levees around nest entrances.

Our study centers on an ant assemblage that occupies the floodplain of the Parana River, one of the world's largest rivers. Because, this region is largely flat with soils consisting of a dense mixture of fine sand and silt, water infiltrates the ground very slowly. Intense summer rain events lead to widespread areas with shallow-standing 
water. Depending upon rain frequency, soil type and microtopography, water will stand in normally dry areas at depths of one to several centimeters from hours to days at a time (E. LeBrun, pers. obs.).

Despite the frequency of this natural disturbance regime, the ground-nesting ants in this region of South America are impressively abundant and diverse (see LeBrun et al., 2007; Tillberg et al., 2007). Following the first local rains in over a month, we observed five distantly related species in this habitat constructing earthen walls immediately adjacent to the lips of their nest entrances: Pheidole cf. obscurithorax, Acromyrmex landolti, Dorymyrmex thorasicus, Ectatomma opaciventre, and Pheidole jelseki. These earthen walls were likely absent prior to the rain due to trampling by cattle during the intervening drought. Inspired by these observations, we conducted a series of manipulations (1) to determine whether these earthen walls protect ant nests from superficial flooding, thus functioning as levees, and (2) to test whether or not the loss of these structures disrupts colony function.

\section{Methods}

This study was conducted in January and February 2009 at two field sites in northern Santa Fe Province, Argentina (Site 1: S $28.49^{\circ}$, W $59.27^{\circ}$; Site 2: S $28.50^{\circ}$, W $59.58^{\circ}$ ). Observations and manipulations were conducted on five species in this assemblage. Pheidole cf. obscurithorax and Pheidole jelseki (Fallax group Wilson, 2003) in the Pheidolini tribe of the subfamily Myrmicinae, primarily scavenge dead insects. Acromyrmex landolti, in the Attini tribe of the subfamily Myrmicinae, is a leaf-cutting, fungus-growing ant. Dorymyrmex thorasicus, in the subfamily Dolichoderinae, is primarily a scavenger of dead insects and obtains food items by rapidly recruiting large numbers of workers. Finally, E. opaciventre, in the subfamily Ectatomminae, is a large, generalist insect predator that captures and retrieves prey items without any form of co-operation. Nest entrances of all species were well spaced, typically 10 or more meters apart, indicating that colonies possess only a single nest entrance per nest.

For Pheidole jelseki, Acromyrmex landolti, and E. opaciventre, we performed manipulations on all colonies that we ere able to find. For Dorymyrmex thorasicus, and Pheidole cf. obscurithorax, we chose colonies that appeared to be at least of average size among those available for the manipulations. More active and presumably larger colonies exhibited longer and more branched nest entrances for Pheidole cf. obscurithorax and larger towers in Dorymyrmex thorasicus. As these towers are constructed from material brought out from the colonies during nest repair (see the "Results"), their size is likely a function of underground nest dimensions, which is a function of colony size.

We experimentally flooded the immediate area surrounding the nest entrances of these five focal species to a depth of $1 \mathrm{~cm}$ to observe whether earthen walls surrounding nest entrances sufficed to prevent floodwaters from entering the nest. To simulate flooding, we placed a plastic ring $27 \mathrm{~cm}$ in diameter and $10 \mathrm{~cm}$ high around each nest entrance. With the bottom edge of the ring buried $1-3 \mathrm{~cm}$ beneath the soil surface, we packed soil around the ring's inside edge so that water introduced inside the ring did not escape. Using a watering can, we sprinkled water inside the ring until water stood to an approximate depth of $1 \mathrm{~cm}$ across the soil surface inside the ring. Depending upon soil type, from 0.5 to 11 of water was required to inundate the area inside the ring. Failure of levee walls was evidenced by structural collapse followed by water pouring into the nest entrance hole. For two common species, D. thorasicus, and E. opaciventre, we conducted additional short and longterm flooding experiments to ascertain how compromised levees affected colony function.

\section{Short-term impact of flooding on colony function}

Using the experimental flooding methods described above, we investigated how levee protection enhanced the ability of replicate pairs of D. thorasicus and E. opaciventre colonies to obtain food. Colonies within each pair received the same quantity of water, and trials at each colony were commenced within $15 \mathrm{~min}$ of one another. Prior to flooding, for treatment colonies, we compromised the integrity of the earthen wall surrounding the nest entrance by removing an approximately $1-\mathrm{cm}$ section of the wall with forceps. Care was taken not to allow dirt from the wall to fall inside the nest entrance, and the majority of the wall was left intact. For control colonies, as a sham treatment, we introduced forceps into the nest entrance to simulate the treatment disturbance. Flooding was not begun until colony activity had resumed, as determined by ants observed leaving the nest entrance. Once the water level had subsided, such that soil was exposed across approximately 50\% of the area within the ring, the trial commenced. We placed three dead insects evenly spaced around the inside edges of the ring. We collected insects (primarily grasshopper nymphs) on site with a sweep net. For both $D$. thorasicus, and E. opaciventre, we recorded the time until colony activity commenced and the time until the first discovery of an insect. For the mass recruiting $D$. thorasicus, we considered the time until 20 ants had recruited to an insect bait as the measure of successful foraging, while for the large-bodied, solitary foraging E. opaciventre, the time until an insect bait was retrieved and carried inside the nest entrance provided the 
final measure of foraging success. Because soil density varied spatially and because ant activity varied with time of day, neighboring conspecific colonies of each of the two species were used as replicate pairs of treatment and control colonies. In each replicate pair, assignment of colonies to experimental groups was determined by means of a coin toss. Because waiting times are geometrically distributed processes, these non-normally distributed data were analyzed with non-parametric Wilcoxon matched pair tests.

\section{Medium-term impact of flooding on colony function}

We performed a second medium-term experiment on colony function in E. opaciventre. Flooding manipulations were conducted in the morning and in a similar manner as in the previous experiment. Treatments differed in that 31 of water were sprinkled into the ring surrounding both levee intact and levee-breached colonies, and the ring was removed as soon as the water had infiltrated the soil. Eight hours after flooding, we measured the level of foraging and nest maintenance activity exhibited by the colony over a 5 -min period. Five minutes was sufficiently long that multiple events of nest maintenance and foraging behavior were observed at all colonies. Foraging activity was assessed as the total number of workers leaving the colony and traveling more than $1 \mathrm{~m}$ away from the nest entrance or returning from more than $1 \mathrm{~m}$ from the colony. Workers traveling more than $1 \mathrm{~m}$ from the nest entrance continued to travel outside the area adjacent to the nest, and workers returning from more than $1 \mathrm{~m}$ appeared to be coming from much further away and typically carried insect prey. Individual foraging bouts by E. opaciventre workers typically last more than $26 \mathrm{~min}$ (see Pie, 2004 for foraging bout durations). Thus, it is unlikely that within the 5 min observation interval individual workers were counted both leaving and returning. Nest maintenance activity was measured as the maximum number of workers observed simultaneously outside the nest, performing nest maintenance work during the 5-min observation window. Workers engaged in nest maintenance emerged from the colony carrying pellets of dirt, traveled about $20 \mathrm{~cm}$ from the nest entrance, deposited the dirt and then returned to the nest. Nest maintenance workers thus occurred close to the nest entrances and were easily identified and counted.

All colonies were flooded nearly simultaneously, with $1 \mathrm{~h}$ being required to flood all treatment and control colonies. Control and treatment colonies were spatially interspersed. Because all flooding treatments and observations occurred within the same activity window, control and treatment replicates were considered independent replicates and were not paired for analysis. Counts of foraging and nest maintenance events were non-normally distributed, and analyzed with non-parametric Wilcoxon tests $\left(\mathrm{JMP}^{\circledR}\right.$, 2000). However, the distribution of overall activity (the sum of foraging plus nest maintenance behaviors) was normally distributed.

\section{Results}

We observed five species that constructed earthen berms around their nest entrance after heavy rains: Pheidole cf. obscurithorax, P. jelseki, Acromyrmex landolti, D. thorasicus, and E. opaciventre (Fig. 1). These structures appeared $24 \mathrm{~h}$ after the first substantial rain in the study region in the preceding month. Previous to these rains, no earthen structures around nest entrances were evident for any ant species in the system (E.G. LeBrun, pers. obs.). Four out of the five species evaluated constructed walls with sheer sides adjacent to their nest entrances (Fig 1a-d). These earthen walls functioned as levees in that they prevented floodwaters of $1 \mathrm{~cm}$ depth from entering nest entrances: $P$. cf. obscurithorax (4/4), A. landolti (2/2), D. thorasicus (7/8), and E. opaciventre (17/17) (number of nest entrances intact post flooding/number of nest entrances experimentally flooded). A final species, $P$. jelseki, constructed a circular earthen berm $3-5 \mathrm{~cm}$ from the entrance to the nest (Fig. 1e). The berms surrounding the nest entrances of the two colonies of $P$. jelseki tested failed when subjected to the flooding treatment. Observations on A. landolti and $P$. jelseki were limited by the local scarcity of colonies of these species.

Pheidole cf. obscurithorax colonies constructed an earthen wall out of small pieces of consolidated sand and silt that ran around the entire perimeter of their elongate and highly irregular nest entrances (Fig. 1a). These entrances consisted of a rounded slit in the ground $1 \mathrm{~cm}$ wide and up to $10 \mathrm{~cm}$ long often curving and sometimes branched. The earthen walls were $2.9 \pm 0.9 \mathrm{~cm}$ high and $8.6 \pm 2.9 \mathrm{~cm}$ (mean $\pm \mathrm{SD}, N=7$ ) wide on their longest axes. Acromyrmex landolti colonies constructed solid earthen towers out of a combination of mud and bits of vegetation (Fig. 1b). These towers were $4.25 \pm 1.1 \mathrm{~cm}$ high and $1.9 \pm 0.2 \mathrm{~cm}$ $(N=3)$ wide at their top. The levees constructed around $D$. thorasicus nest entrances were $1.5 \pm 0.5 \mathrm{~cm}$ tall and round with a diameter of $4.4 \pm 0.6 \mathrm{~cm}(N=9)$ at the top. Composed of small pellets of consolidated sand and silt, these structures often flared outwards from the base to the lip, giving them a champagne flute-like geometry (Fig. 1c). The levees surrounding $E$. opaciventre colonies were circular, straight-sided towers $2.1 \pm 0.8 \mathrm{~cm}$ high by $2.4 \pm 0.3 \mathrm{~cm}$ wide $(N=11)$ (Fig. 1d). These towers were constructed of balls of mud packed together and then hardened in the sun. The earthen walls around $P$. jelseki colonies consisted of a circular ring of unconsolidated sand and silt $5 \mathrm{~cm}$ from the nest entrance (Fig. 1e). 

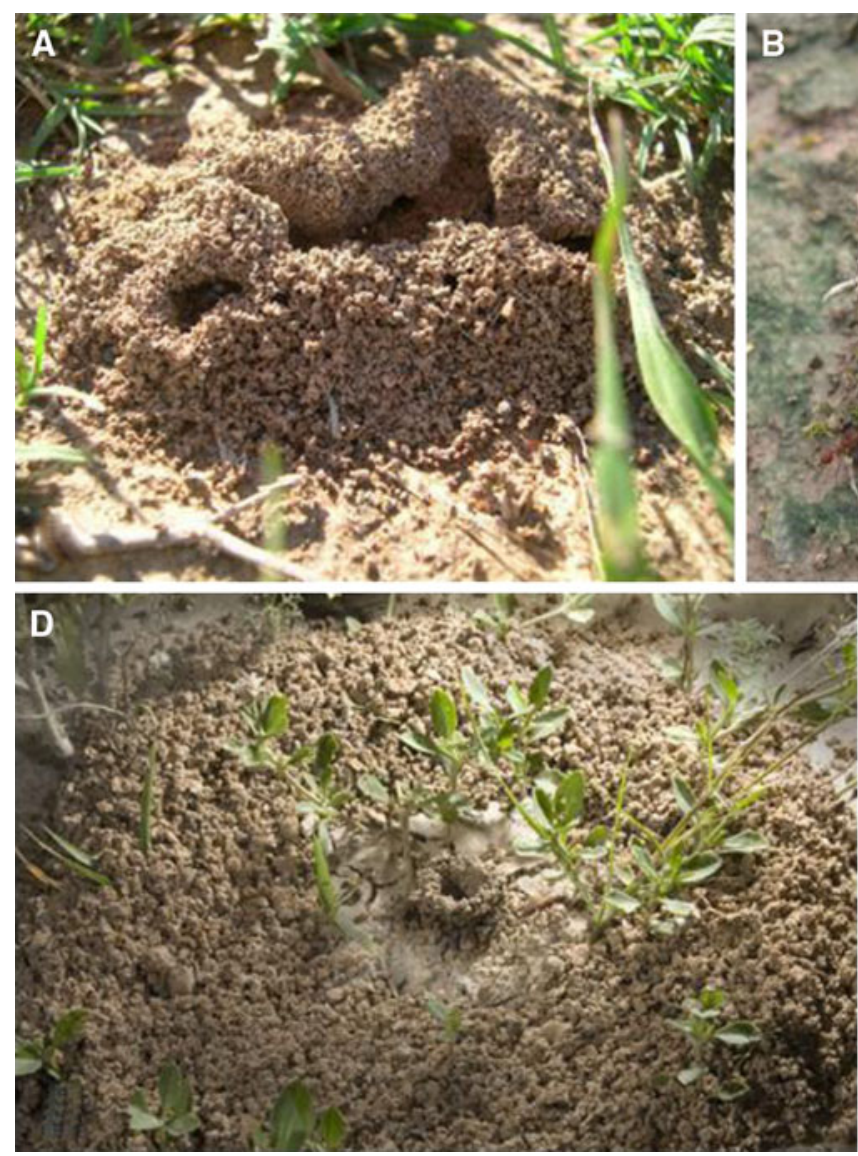

Fig. 1 Levee structures surrounding nest entrances of five distantly related ant species: a Pheidole cf. obscurithorax (Myrmicinae), b Acromyrmex landolti (Myrmicinae), c Dorymyrmex thorasicus

Short-term impact of flooding on colony function

Breaching levees around nest entrances immediately prior to flooding events led to a significant, and substantial increase in the amount of time required for colonies of D. thorasicus to recruit 20 workers to a nearby insect resource (levees intact: 8.0 [3.9-12.7] min; levees breached: 16.8 [11.6-53.5] min, median (interquartile range); Wilcoxon matched pairs test: $N=6, P<0.04$ ) (Fig. 2). However, whether or not, these levees were breached did not notably impair a colony's ability to discover nearby food items (levees intact: 1.8 [1.1-3.8] min; levees breached: 2.1 [1.4-4.8] min; Wilcoxon matched pairs test: $N=6, P=0.16$ ). Nest maintenance behaviors (e.g., ants carrying dirt from inside the nest and depositing it outside) were observed in all treatment colonies, but were rarely observed in controls. Levee reconstruction did not commence immediately after flooding, but by the following day all breached colonies had repaired gaps in their levee walls.

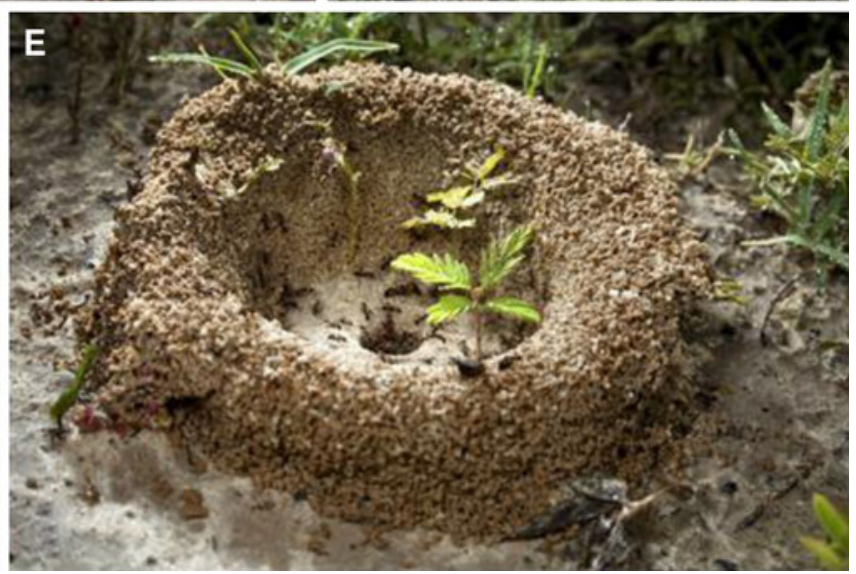

(Dolichoderinae), d Ectatomma opaciventre (Ectatomminae), and e Pheidole jelseki (Myrmicinae)

Ectatomma opaciventre colonies with levees breached prior to flooding required significantly longer to retrieve nearby insect prey compared with colonies with intact levees (levees intact: 2.3 [1.6-4.8] min; levees breached: 10.7 [5.2-17.8] min; Wilcoxon matched pairs test: $N=7$, $P<0.02$ ) (Fig. 2). However, as in D. thorasicus, there was no significant difference in the time required to discover nearby food items (levees intact: 1.0 [0.6-3.3] min; levees breached: 1.6 [1.1-6.8] min; Wilcoxon matched pairs test: $N=7, P=0.8$ ). After breaching a wall and flooding an E. opaciventre colony, tower reconstruction began within $30 \mathrm{~min}$ and gaps were often fully repaired within an hour. Workers repairing levees emerged from inside the nest carrying round balls of mud in their mandibles. These workers placed individual mud balls into the breach and worked the surrounding soil with their mandibles to integrate it into the tower structure. All work was performed from inside the lengthening tube. After levees had been repaired to their original stature, additional dirt removed from inside the nest was taken approximately $15 \mathrm{~cm}$ away 

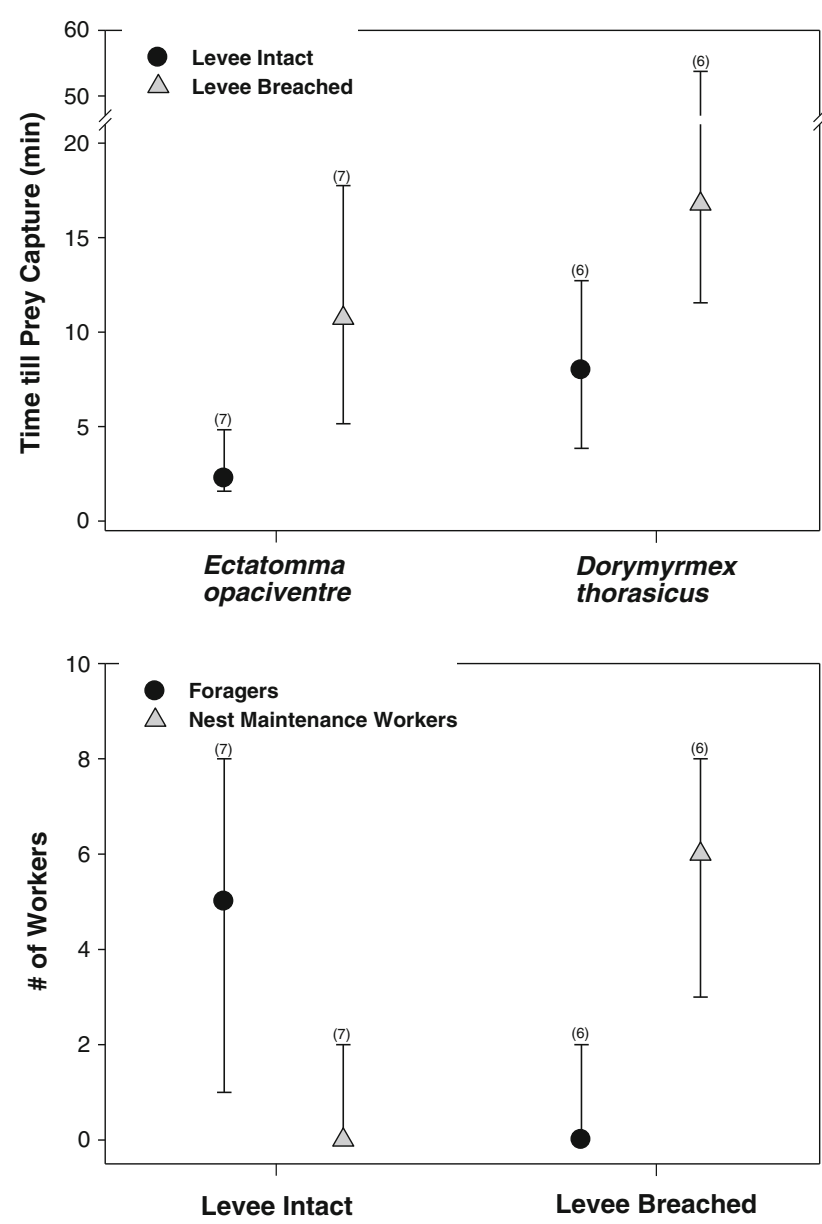

Fig. 2 Results of flooding manipulations. Symbols and bars display the median response and the 25th and 75th quartiles of the data, respectively. Numbers in parentheses above the bars indicate the number of colonies manipulated. a Results of the short-term flooding experiment. This experiment quantified how experimental flooding and levee integrity affects the ability of Dorymyrmex thorasicus and Ectatomma opaciventre colonies to obtain insect resources placed near nest entrances. For both species, the time until prey capture was significantly longer when levees surrounding nest entrances were breached. b Results of the medium-term flooding experiment. This experiment quantified how experimental flooding of $E$. opaciventre colonies with intact or breached levees affects their ability to allocate workers between foraging and nest maintenance $8 \mathrm{~h}$ post flood. Under experimental flooding, levee integrity strongly affected the number of workers engaged in different tasks

from the entrance and deposited in a loose, unconsolidated ring (Fig. 1d).

Medium-term impact of flooding on colony function

Flooding strongly affected the expression of foraging versus nest maintenance behavior. Eight hours post flooding, E. opaciventre colonies with breached levees at the time of flooding exhibited significantly less foraging activity (sum of leaving and returning foragers) compared with colonies with intact levees (levees intact: 5 [1-8] workers; levees breached: 0 [0-2] workers, median (interquartile range); Wilcoxon test: $N=7, P<0.02$ ). In addition,colonies with breached levees engaged in significantly more nest maintenance activity than did colonies with intact levees (levees intact: 0 [0-2] workers; levees breached: 6 [3-8] workers; Wilcoxon test: $N=7, P<0.003$ ] (Fig. 2). However, overall activity level was not impacted. There was no difference in the overall activity level (sum of all workers-behaviors observed) between colonies with breached or intact levees (levees intact: 5 [3-8] workers; levees breached: 6 [3-9] workers; Wilcoxon test: $N=7$, $P=0.52)$.

\section{Discussion}

Whether the soil excavated from a nest during repair or expansion protects colonies against future inundation depends upon whether the behaviors of the ants determining the pattern of soil deposition create a barrier surrounding the nest entrance of sufficient structural integrity to resist floodwaters. In this study, four out of five species constructed conspicuous earthen walls around their nest entrances primarily with dirt excavated from inside the nest. These walls formed functional levees, preventing floodwaters from entering nests that were experimentally challenged with shallow inundations. However, berms constructed around the entrances of $P$. jelseki nests failed when subjected to this type of flooding, allowing water and dirt to wash into nest entrances. The failure of berms surrounding $P$. jelseki nest entrances demonstrates that not all soil depositional behaviors result in structures that resist inundation.

Analyses of the effects of flooding on the foraging ability of D. thorasicus and E. opaciventre reveal that functional levees provide substantial benefits to colonies. When levees surrounding nest entrances were breached prior to flooding, both ant species required more time to retrieve insect prey (E. opaciventre) or to recruit nestmates to such resources (D. thorasicus). Although rates of resource discovery did not differ for either species as a result of experimental flooding, our experimental protocol may not have allowed for the normal expression of resource scouting and discovery behavior. Resources were presented close to nest entrances and as a result, there was no clear way to differentiate resource discovery by scouting foragers from random resource encounter. In the breached levee treatments, ants that discovered resources bumped into the food items but generally did not spend time antennating these resources to assess their value and often did not return immediately to the nest to communicate their discovery. Thus, these ants were likely not in a behavioral scouting mode. 
The impact of flooding on foraging activity is prolonged. Eight hours post flood, E. opaciventre colonies with breached walls still exhibited compromised foraging ability compared with colonies with intact levees. Foraging was almost non-existent in colonies that had compromised towers during flooding with all evident worker activity directed toward removing material from the nest, a behavior that was essentially absent in the intact tower treatment. Thus, there was a shift in the functional allocation of work within colonies from foraging to nest maintenance, and it appears that the ability of a colony to secure resources was preempted by the need to repair the internal structure of the nest.

However, it is unclear whether this shift in the functional allocation of work arose from individual workers changing tasks or from changes in the relative activity levels of workers dedicated to particular tasks. Studies of task allocation within the genus Ectatomma universally report temporal polyethism with foraging performed by the oldest workers (Antonialli-Junior and Giannotti, 2003; Corbara, 2000; Locher et al., 2009; Pie, 2002). However, the worker population involved in nest excavation is unclear. In $E$. edentatum, younger workers performed nest maintenance (Antonialli-Junior and Giannotti, 2003), while in a study of E. opaciventre, nest maintenance and foraging were performed by adults and not recently emerged workers, but whether individual workers could engage in both foraging and nest maintenance at the same developmental stage was not addressed (Pie, 2002). Further work is required to understand how this functional shift in task performance arises.

Landscape scale, seasonal flooding profound alters the diversity and structure of terrestrial ant assemblages by reducing abundance, typically reducing species richness, altering species composition (Lude et al., 1999; Mertl et al., 2009; Vasconcelos et al., 2010), and increasing assemblage heterogeneity (Ballinger et al., 2007). However, we know about no studies examining how frequent, superficial flooding immediately after heavy rains influence the organization of ant communities or the foraging behavior of individual species. Rapid resumption of foraging activity after heavy rains may confer important advantages. Dead insects are common after hard rains and low-level flooding (E. LeBrun, pers. obs.), and the data herein suggest that colonies with broken levees (and colonies of ant species that do not construct levees) may forage at reduced rates following precipitation events. Thus, the time window immediately after a heavy rain event likely represents a rich foraging opportunity for ant colonies and those that can return to normal activity rapidly enjoy a period of relaxed competition for a rich resource pool. Access to this window may form an important component of the niches of ant species common in these environments and one that may help to explain patterns of co-existence in this highly competitive system. Not all behavioral adaptations to superficial flooding provide the ability to rapidly resume foraging after rains. For example, colonies of competitively dominant Argentine ants (Linepithema humile), in the same ecosystems examined in the present study, retreat up into trees and shrubs, while securing their brood under bark or in hollow stems. The reoccupation of areas that they abandon as standing water rises can take several days (E. LeBrun, pers. obs.).

Although our flooding treatment mimicked superficial flooding after a heavy rain with respect to the depth of the standing water (E. LeBrun, pers. obs.), water stood for only a minute or so in our manipulations, while after natural rain events water can stand for minutes to days depending upon rain intensity, soil type and microtopography. Our results likely reflect the behavior of colonies after low to moderate intensity rainfall, but it is unclear whether these levees provide benefits after torrential rain events. Our measures of competitive function, resource discovery and retrieval times, likely underestimate the impact of flooding on foraging success under natural conditions. A defining feature of this ant assemblage is the speed and intensity of competition for food resources (LeBrun et al., 2007). Because food items were placed inside plastic rings, potential competitors were absent from all trials. In the presence of competitors, colonies of D. thorasicus and E. opaciventre in the breached wall trials would have almost certainly lost insect food items to neighboring colonies.

Although the levees examined here offer qualitatively similar protective benefits, they are structurally diverse and characteristic of individual species (Fig. 1). For example, $E$. opaciventre colonies construct solid mud wall towers that are higher than they are wide and have nearly vertical faces both inside and out. The structural integrity of these towers arises in part from a salivary protein the ants incorporate into the mud (Antonialli-Junior and Gianotti, 1997). Both $D$. thorasicus and $P$. obscurithorax construct structures out of less consolidated soil. As a result, both are more susceptible to collapse. The levee building behavior shared by the phylogenetically disparate members of this floodplain ant assemblage represents convergent evolution of a functionally important trait in response to a shared selective regime (e.g., Fowler, 1987; Kleineidam et al., 2001; Korb, 2003).

Acknowledgments We would like to thank Shawn Wilder, Melissa Wells, the owners and staff of the Hotel Ychoalay (Villa Ocampo), and I.C. Quilmes for assisting and supporting fieldwork. We thank Andy Suarez and an anonymous reviewer for helpful comments on the manuscript. We appreciate Oreste Pividori for allowing access to his land, and the Brackenridge Field Laboratory for logisitical support. Christian Rabeling provided assistance with the identification of the Acromyrmex species. The National Science Foundation (DEB 07-16966 to DAH) provided funding.

Open Access This article is distributed under the terms of the Creative Commons Attribution Noncommercial License which permits 
any noncommercial use, distribution, and reproduction in any medium, provided the original author(s) and source are credited.

\section{References}

Antonialli-Junior W.F. and Giannotti E. 2003. Temporal polyethism in workers of Ectatomma edentatum (Formicidae : Ponerinae). Sociobiology 41: 461-478

Antonialli-Junior W.F. and Gianotti E. 1997. Nest architecture and population dynamics of the ponerine ant Ectatomma opaciventre Roger (Hymenoptera: Formicidae). J. Adv. Zool. 18: 64-71

Ballinger A., Lake P.S. and Mac Nally R. 2007. Do terrestrial invertebrates experience floodplains as landscape mosaics? Immediate and longer-term effects of flooding on ant assemblages in a floodplain forest. Oecologia 152: 227-238

Corbara B. 2000. Self-organization in the division of labor in incipient societies of the ant Ectatomma ruidum (Formicidae : Ponerinae): Emergence of an age polyethism. Sociobiology 36: 447-464

Fowler H.G. 1987. The nest of Pheidole oxyops as a pitfall-trap (Hymenoptera, Formicidae). Pedobiologia 30: 373-376

Hölldobler B. and Wilson E.O. 1990. The Ants. Belknap Press of Harvard University Press, Cambridge Massachusetts

JMP $^{\circledR}$ 2000. JMP Statistics and Graphics Guide, Version 4. SAS Institute Inc., Cary North Carolina

Klein R.W., Maschwitz U. and Kovac D. 1993. Flood-control by Ants a Southeast-Asian bamboo-dwelling Tetraponera (Formicidae, Pseudomyrmecinae) Bails Water from Its Internode Nests. Insect. Soc. 40: 115-118

Kleineidam C., Ernst R. and Roces F. 2001. Wind-induced ventilation of the giant nests of the leaf-cutting ant Atta vollenweideri. Naturwissenschaften 88: 301-305

Korb J. 2003. Thermoregulation and ventilation of termite mounds. Naturwissenschaften 90: 212-219

LeBrun E.G., Tillberg C.V., Suarez A.V., Folgarait P.J., Smith C.R. and Holway D.A. 2007. An experimental study of competitive interactions between red imported fire ants and Argentine ants in a region of native-range sympatry. Ecology 88: 63-75
Locher G.D., Giannotti E. and Tofolo V.C. 2009. Brood care behavior in Ectatomma brunneum (Hymenoptera, Formicidae, Ectatomminae) under laboratory conditions. Sociobiology 54: 573-587

Lude A., Reich M. and Plachter H. 1999. Life strategies of ants in unpredictable floodplain habitats of Alpine rivers (Hymenoptera : Formicidae). Entomol. Gen. 24: 75-91

Maschwitz U. and Moog J. 2000. Communal peeing: a new made of flood control in ants. Naturwissenschaften 87: 563-565

Mertl A.L., Wilkie K.T.R. and Traniello J.F.A. 2009. Impact of flooding on the species richness, density and composition of Amazonian litter-nesting ants. Biotropica 41: 633-641

Moffett M. 2010. Adventures Among Ants. University of California Press, Berkeley

Morrill W.L. 1974. Dispersal of red imported fire ants by water. Fla. Entomol. 57: 39-42

Nielsen M.G., Christian K. and Birkmose D. 2003. Carbon dioxide concentrations in the nests of the mud-dwelling mangrove ant Polyrhachis sokolova Forel (Hymenoptera : Formicidae). Aust. J. Entomol. 42: 357-362

Nielsen M.G., Christian K., Henriksen P.G. and Birkmose D. 2006. Respiration by mangrove ants Camponotus anderseni during nest submersion associated with tidal inundation in Northern Australia. Physiol. Entomol. 31: 120-126

Pie M. 2004. Foraging ecology and behavior of the ponerine ant Ectatomma opaciventre Roger in a Brazilian savannah. J. Nat. Hist. 38: 717-729

Pie M.R. 2002. Behavioral repertoire, age polyethism and adult transport in Ectatomma opaciventre (Formicidae : Ponerinae). $J$. Insect Behav. 15: 25-35

Tillberg C.V., Holway D.A., LeBrun E.G. and Suarez A.V. 2007. Trophic ecology of invasive Argentine ants in their native and introduced ranges. Proc. Natl Acad. Sci. USA 104: 20586-20861

Vasconcelos H.L., Vilhena J.M.S., Facure K.G. and Albernaz A. 2010. Patterns of ant species diversity and turnover across $2000 \mathrm{~km}$ of Amazonian floodplain forest. J. Biogeog. 37: 432-440

Wilson E.O. 1986. The organization of flood evacuation in the ant genus Pheidole (Hymenoptera: Formicidae). Insect. Soc. 33: 458-469 